ORIGINAL ARTICLE

\title{
Self-fertilization in mosses: a comparison of heterozygote deficiency between species with combined versus separate sexes
}

\author{
SM Eppley, PJ Taylor and LK Jesson \\ School of Biological Sciences, Victoria University of Wellington, Wellington, New Zealand
}

\begin{abstract}
Self-fertilization is a key difference of adaptive significance between species with combined versus separate sexes. In haploid-dominant species such as mosses and ferns, species with either combined or separate sexes (monoicous and dioicous, respectively) have the potential to self-fertilize (intergametophytic selfing), but being monoicous allows an additional mode of selfing (intragametophytic selfing). We used allozyme electrophoresis to estimate deviations from expected levels of heterozygosity under Hardy-Weinberg equilibrium to infer selfing rates in 10 moss species from 36 New Zealand populations. We found that while there were deficiencies of heterozygotes compared to expectation in both monoicous and dioicous mosses, monoicous species had significantly higher levels of heterozygote deficiency
\end{abstract}

than dioicous species $\left(F_{\mathrm{IS}}=0.89 \pm 0.12\right.$ and $0.41 \pm 0.11$, respectively). Estimated selfing rates suggest that selfing occurs frequently in monoicous populations, and rarely in dioicous populations. However, in two dioicous species (Polytrichadelphus magellanicus and Breutelia pendula), we found significant indications of mixed mating or biparental inbreeding in a handful of populations. These data provide the first analysis of heterozygote deficiency and selfing among haploid-dominant species with breeding system variation, and we discuss our results with respect to the consequences of inbreeding depression and the evolution of breeding systems.

Heredity (2007) 98, 38-44. doi:10.1038/sj.hdy.6800900; published online 27 September 2006

Keywords: breeding system; moss; dioicous; mating system; monoicous; plant

\section{Introduction}

Breeding systems influence patterns of genetic diversity because they govern the transmission of genes between generations. The breeding systems that offer the starkest contrasts are those with organisms expressing both sex functions in an individual (hermaphroditism) versus those with only a single sex function, as hermaphrodites have the potential to self-fertilize. Population genetic theory predicts that selfing may be selected against because it increases levels of homozygosity in offspring, which in turn, allows the expression of recessive, deleterious alleles (Fisher, 1949; Wright, 1965; Nei et al., 1975; Charlesworth and Charlesworth, 1998). On the other hand, once deleterious alleles are purged from the genome, selfing can be adaptive because a selfer can fertilize both its own eggs and the eggs of others in the population (Fisher, 1949). Theoretical models predict that both selfing and outcrossing are stable states, depending on levels of inbreeding depression (Lande and Schemske, 1985), and general surveys in angiosperms reveal that both complete selfing and complete outcrossing commonly occur (Barrett and Eckert, 1990). However,

Correspondence: Dr SM Eppley. Current address: Department of Biology, Portland State University, PO Box 751, Portland, OR 97207-0751, USA E-mail: eppley@pdx.edu

Received 13 April 2006; revised 21 August 2006; accepted 24 August 2006; published online 27 September 2006 the distribution of selfing rates in other taxa with breeding system variation is less known (e.g. Jarne and Charlesworth, 1993; Carlon, 1999).

The consequences of selfing in populations will depend not only on the breeding system but also on whether the dominant life stage of the organism is haploid and/or diploid (Hedrick, 1987a,b; Otto and Marks, 1996). In animals and seed plants the dominant life stage is diploid (referred to as a sporophyte in plants) and can have either combined or separate sexes while in many nonseed plants, such as some ferns and bryophytes, variation in sexual form occurs at the haploid stage (gametophyte). Whereas selfing in diploid organisms results in a 50\% reduction in heterozygosity, in haploid organisms, selfing can occur in more than one fashion and can result in more than a 50\% reduction in heterozygosity (Klekowski, 1979). Mating between gametes from different haploid individuals produced from the same diploid parent (intergametophytic selfing) results in a 50\% reduction in homozygosity, which is equivalent to selfing in animals and seed plants. In contrast, mating between gametes produced from the same haploid individual (intragametophytic selfing) results in complete homozygosity in a single generation (Hedrick, 1987a).

Several methods exist to estimate levels of selfing in homosporous ferns and mosses. Hedrick (1987b) showed that if inbreeding equilibrium is assumed (e.g. selfing is constant between generations), then the two different 
types of selfing can be estimated from:

$$
F_{\mathrm{e}}=\frac{S+2 S_{\mathrm{I}}}{2-S}
$$

where $F_{\mathrm{e}}$ is the equilibrium inbreeding coefficient, $S$ is the proportion of the progeny in a population produced by intergametophytic selfing and $S_{\mathrm{I}}$ is the proportion produced by intragametophytic selfing. Thus, if the level of selfing within gametophytes $\left(S_{\mathrm{I}}\right)$ is assumed to be zero (e.g. as in dioicous mosses), the above equation can be rearranged to estimate selfing between gametophytes $(S)$ :

$$
S=\frac{2 F_{\mathrm{e}}}{1+F_{\mathrm{e}}}
$$

which is analogous to selfing in seed plants (Wright, 1968). Similarly, if there is no selfing between gametophytes then the level of selfing within gametophytes is:

$$
S_{\mathrm{I}}=F_{\mathrm{e}}
$$

(see McCauley et al., 1985; Holsinger, 1987). As intragametophytic selfing results in equilibrium proportions in only one generation (McCauley et al., 1985), the assumption of equilibrium conditions for Eq. (3) will always apply. In this way, assuming the absence of other factors (e.g. no selection, genetic drift or microspatial population structuring), Wright's fixation index $\left(F_{\mathrm{IS}}\right)$ is equal to the inbreeding coefficient $\left(F_{\mathrm{e}}\right)$ and thus can be used to estimate an amalgam of both intergametophytic and intragametophytic selfing in haploid-dominant species with combined sexes and intergametophytic selfing in haploid-dominant species with separate sexes. While many studies have used $F_{\mathrm{IS}}$ as an estimate of selfing in homosporous ferns (by assuming that intergametophytic selfing is not present; for example McCauley et al., 1985; Holsinger, 1987), in populations with significant levels of heterozygosity in two unlinked loci, Ritland's (1990) maximum likelihood method can be used to estimate both types of selfing. Low levels of heterozygosity are characteristic of many populations of mosses (Shaw, 2000), and therefore this method has only limited application.

While some data exist on levels of average genetic variation in ferns and mosses (McCauley et al., 1985; Shaw, 1991; Shaw, 2000) and on levels of intragametophytic selfing in ferns (McCauley et al., 1985; Holsinger, 1987; Ritland et al., 1990; Soltis and Soltis, 1992), there is a paucity of data examining how variation in breeding system influences deviations from expected levels of heterozygosity or other measures of self-fertilization rates at the diploid stage of haploid-dominant species (see Wyatt and Anderson, 1984; Wyatt, 1994; Shaw, 2000). In particular, it is important to compare selfing rates between populations with combined and separate sexes in haploid-dominant species, as individuals with combined sexes can experience both inter- and intragametophytic selfing, whereas individuals with only one sex function can only engage in intergametophytic selfing (for review see Wyatt and Anderson, 1984). We are unaware of any studies that have made this comparison, despite the important ecological and genetic consequences caused by differential levels of inbreeding depression and genetic diversity in natural populations. In this study we compared deviations from expected levels of heterozygosity in five moss species with combined sexes (monoicous) and five with separate sexes (dioicous). Specifically, we used allozyme markers to estimate Wright's coefficient of inbreeding $\left(F_{\mathrm{IS}}\right)$ in order to (1) test the hypothesis that populations of monoicous and dioicous mosses differ significantly in the amount they deviate from expected levels of heterozygosity, with dioicous populations predicted to have an excess of heterozygotes compared with monoicous populations due to lower levels of selfing and (2) to generate estimates of self-fertilization rates in species of mosses with monoicous and dioicous breeding systems.

\section{Materials and methods}

\section{Population sampling}

We sampled 35 moss species from New Zealand between December 2003 and July 2005. Population coordinates are available from the authors on request. From these species we selected 10 study species (five monoicous and five dioicous) that had: (1) three or more known populations containing sporophytes, and (2) sporophytes showing polymorphism at PGM or PGI allozyme loci either within or between populations. We collected at least 25 sporophytes from each population, unless a population had fewer than 25 individuals (which was true for three populations; Table 1), in which case we collected the entire population. If a population was not discrete, and therefore did not have distinct edges, for instance, a species that occurred continuously along a roadside, we sampled sporophytes for a subsection stretching approximately $100 \mathrm{~m}$. To increase the number of sampled genets, we maximized the distance between sampled sporophytes within each population or subsection of nondiscrete populations. Although genetic variation can be low in many moss gametophytic populations due to gametophytic clonal growth (Shaw, 2000), this did not constrain our ability to sample large numbers of distinct sporophytic genets in such populations because by definition each sporophyte is a separate genet created by a single fertilization event and cannot spread vegetatively. Sporophyte samples were stored at $4^{\circ} \mathrm{C}$ and used for allozyme electrophoresis within 3 weeks.

\section{Allozyme electrophoresis}

We used starch gel electrophoresis to screen sporophyte tissue of all species for variation at 16 allozyme markers. Sporophyte capsules were ground in a drop of extraction buffer $(100 \mathrm{ml} 0.1 \mathrm{M}$ Tris- $\mathrm{HCl}(\mathrm{pH} 7.5), 2$ drops $(0.2 \%)$ 2-mercaptoethanol, $0.04 \mathrm{~g}$ ethylenediamine- $N, N, N^{\prime}, N^{\prime}$ tetraacetic acid (EDTA)-3Na salt, $0.23 \mathrm{~g} 10 \mathrm{mM} \mathrm{MgCl}_{2}$, $0.08 \mathrm{~g} 10 \mathrm{~mm} \mathrm{KCl}, 0.1 \mathrm{ml}(0.1 \%)$ Triton X-100 and $5 \mathrm{mg}$ polyvinylpolypyrrolidone per $0.2 \mathrm{ml}$ ). A TEB electrode buffer system (0.5 M Tris, $0.016 \mathrm{M}$ EDTA, $0.57 \mathrm{M}$ Boric acid, $\mathrm{pH} 8.0$ and diluted 1:10 for the gel buffer) was used to separate enzymes. Wicks containing extract were run in electrophoresis tanks on $2.5 \%$ starch gels for 20 min after which time the wicks were removed, and gels were run for a further $3 \mathrm{~h}$ at $180 \mathrm{~V}$. Staining protocols followed Soltis and Soltis (1989).

We focused on PGM and PGI because all 10 species were variable and resolvable at one or two loci of $P G M$, and a subset of species were also variable for PGI. Variability at the other 14 allozyme markers was 
Table 1 Summary of Wright's $F_{\text {IS }}$ values for monoicous and dioicous mosses

\begin{tabular}{|c|c|c|c|c|c|c|c|c|}
\hline Species (location) & Breeding system & Habitat & $\mathrm{N}$ & $\operatorname{Loci}(\mathrm{N})$ & $\mathrm{F}_{I S}$ & $S$ & $\mathrm{P}(\mathrm{S}=0)$ & $\mathrm{P}(\mathrm{S}=1)$ \\
\hline Acrocladium chlamydophyllum & Monoicous & & 87 & & 0.62 & & & \\
\hline Harwood's Hole & & Forest understorey & 32 & 2 & 1 & - & 0.844 & $0.000^{*}$ \\
\hline Glenorchy & & Forest understorey & 41 & 1 & -0.14 & - & 0.182 & 1.000 \\
\hline Papatowai & & Forest understorey & 14 & 1 & 1 & - & 0.359 & 1 \\
\hline Funaria hygrometrica & Monoicous & & 228 & & 0.98 & & & \\
\hline Akatarawa Road & & Roadside & 35 & 3 & 0.95 & - & $0.000^{*}$ & 0.779 \\
\hline Khandallah & & Garden & 25 & 2 & 1 & - & 0.123 & 1 \\
\hline Otari Wilton's Bush & & Pathway & 25 & 2 & 0.93 & - & $0.004^{*}$ & 0.682 \\
\hline Queenstown & & Garden & 64 & 2 & 1 & - & 0.134 & 1 \\
\hline Victoria University & & Greenhouse & 51 & 2 & 1 & - & 0.365 & 1 \\
\hline Wairau Falls & & Riverbank & 28 & 2 & 1 & - & $0.001^{*}$ & 1 \\
\hline Rhynchostegium tenuifolium & Monoicous & & 81 & & 0.85 & & & \\
\hline Belmont Regional Park & & Forest understorey & 27 & 1 & 1 & - & $0.000^{*}$ & 1 \\
\hline Orongorongo Valley & & Forest understorey & 25 & 1 & 1 & - & 0.357 & 1 \\
\hline Otari Wilton's Bush & & Forest understorey & 29 & 2 & 0.55 & - & 0.352 & 0.500 \\
\hline Syntrichia antartica & Monoicous & & 117 & & 0.83 & & & \\
\hline Otari Wilton's Bush & & Wall & 36 & 3 & 1 & - & 0.365 & 1 \\
\hline Wellington Botanic Gardens & & Wall & 51 & 2 & 0.5 & - & 0.725 & 0.358 \\
\hline Orongorongo Valley & & Coastal rocks & 30 & 1 & 1 & - & NA & NA \\
\hline Tortula muralis & Monoicous & & 99 & & 0.92 & & & \\
\hline Okato & & Wall & 27 & 2 & 0.77 & - & $0.003^{*}$ & 0.502 \\
\hline Khandallah & & Wall & 40 & 1 & 1 & - & $0.000^{*}$ & 1 \\
\hline Victoria University & & Wall & 32 & 2 & 1 & - & 0.679 & 1 \\
\hline Breutelia pendula & Dioicous & & 187 & & 0.29 & & & \\
\hline Akatarawa Road & & Roadside & 29 & 3 & 0.69 & 0.82 & 0.695 & $0.000^{*}$ \\
\hline Bryophyte Gully & & Roadside & 41 & 2 & 1 & 1 & 0.721 & 0.497 \\
\hline Glenorchy & & Forest gap & 56 & 3 & -1 & -1 & 0.342 & 0.658 \\
\hline Kaitoke & & Forest gap & 61 & 2 & 0.45 & 0.62 & $0.000^{*}$ & $0.000^{*}$ \\
\hline Hypnodendron arcuatum & Dioicous & & 85 & & 0.17 & & & \\
\hline Butterfly Creek & & Forest understorey & 30 & 3 & 0.93 & 0.96 & 0.217 & 0.684 \\
\hline Haast & & Forest understorey & 30 & 2 & -0.05 & -0.11 & 0.544 & 0.177 \\
\hline Kaitoke & & Forest understorey & 25 & 1 & -0.37 & -1.17 & 1 & $0.000^{*}$ \\
\hline Hypopterygium filiculaeforme & Dioicous & & 115 & & 0.62 & & & \\
\hline Belmont Regional Park & & River bank & 88 & 2 & 0.49 & 0.66 & 0.319 & 0.507 \\
\hline Orongorongo Valley & & Forest understorey & 12 & 3 & 1 & NA & NA & NA \\
\hline Otari Wilton's Bush & & River bank & 15 & 2 & 0.38 & 0.55 & 0.906 & $0.000^{*}$ \\
\hline Macromitrium longipes & Dioicous & & 112 & & 0.16 & & & \\
\hline Glenorchy & & Forest understorey & 27 & 2 & 0.36 & 0.53 & 0.994 & $0.000^{*}$ \\
\hline Kaitoke & & Forest understorey & 27 & 3 & 0.45 & 0.62 & 0.502 & $0.019^{*}$ \\
\hline Milford Sound & & Forest understorey & 33 & 2 & 0.06 & 0.11 & 0.493 & $0.000^{*}$ \\
\hline Washbourne Reserve & & Forest understorey & 25 & 2 & -0.22 & -0.56 & 0.841 & 0.064 \\
\hline Polytrichadelphus magellanicus & Dioicous & & 177 & & 0.97 & & & \\
\hline Ảkatarawa Road & & Roadside & 44 & 3 & 1 & 1 & $0.001^{*}$ & 1 \\
\hline Bryophyte Gully & & Roadside & 27 & 3 & 0.98 & 0.98 & 0.079 & 0.798 \\
\hline Glenorchy & & Forest gap & 81 & 3 & 1 & 1 & $0.000^{*}$ & 0.186 \\
\hline Papatowai & & Garden & 25 & 3 & 0.91 & 0.95 & 0.359 & 1 \\
\hline
\end{tabular}

Values of $F_{\text {IS }}$ in bold are species means (total sample size is given italics). $F_{\text {IS }}$ in monoicous mosses is an amalgam of intergametophytic and intragametophytic selfing. $S$ is intergametophytic selfing in dioicous mosses; $P$-values followed by * are significant at the $\alpha=0.05$ level.

generally low, and because of the small size of the sporophytes, resolution was often insufficient for scoring. To eliminate the confounding effects of fixed heterozygosity through polyploidy, for a subset of individuals for each species, we separately electrophoretically assayed the gametophyte (haploid) as well as the sporophyte (diploid) tissue. Using these results, we only scored a locus if a band was consistently absent from some gametophytic individuals. With this information, we were able to unam biguously score every individual as either a heterozygote or a homozygote.

\section{Population statistics and estimation of selfing rates}

For each population, we calculated Wright's inbreeding coefficient $\left(F_{\mathrm{IS}}\right)$, as a measure of divergence of the 
proportion of heterozygotes from those expected under the assumptions of Hardy-Weinberg equilibrium, following Hartl and Clark (1997). Additionally, we estimated $\left(F_{\mathrm{ST}}\right)$ as a measure of population differentiation, using POPGENE (Yeh et al., 1997).

There was insufficient heterozygosity in either the monoicous or dioicous species in this study to use existing algorithms that estimate levels of intergametophytic and intragametophytic selfing (Ritland et al., 1990). Instead we used the indirect approach for measuring intragametophytic selfing rates described above (McCauley et al., 1985; Hedrick, 1987b; Holsinger, 1987). For the monoicous mosses we examined $F_{\text {IS }}$ as a measure of both intergametophytic and intragametophytic selfing, and for the dioicous species, selfing rates were estimated using Eq. (2) above. One monoicous and one dioicous population were monomorphic for all loci examined, and we were therefore unable to estimate selfing rates for these two populations. While these estimates of selfing are insightful for each breeding system, we did not test for differences between the two estimates because each mode of selfing has different genetic consequences.

\section{Data analyses}

To assess how breeding system (a fixed effect) and species (a random effect, nested in breeding system) affected $F_{\text {IS }}$ we used a mixed model, nested analysis of co-variance ANCOVA (using EMS variance calculations because REML calculations violated model assumptions) using JMP (SAS Institute, 2004). As not all loci were resolvable and variable for all species, the number of loci that was scored was included as a covariate. The residuals were normally distributed, and variances were homogeneous. To analyse the effects of breeding system on $F_{\mathrm{ST}}$, and to determine if either $F_{\mathrm{IS}}$ or $F_{\mathrm{ST}}$ differed from zero in either dioicous or monoicous mosses, we used a Student's $t$-test of species means, with no assumption of equal variances.

To assess whether estimated selfing rates differed from zero or one, we used a nonparametric bootstrapping technique described by Johnston et al. (1998) that examines whether levels of heterozygosity are significantly different than expectation. We chose to bootstrap levels of heterozygosity rather than selfing rates as resampling the observed genotypes could result in samples with no expected heterozygosity, and in these samples $S$ could not be calculated. For each of 10000 iterations we randomly sampled with replacement the observed genotypes of individuals in a population $N$ times (where $N$ is the number of individuals in a population). If a population was polymorphic for more than one locus, each locus was chosen with equal probability. From this resampled data, we used the allele frequency to calculate the expected heterozygosity. Hedrick (1987a) showed that the expected heterozygosity (assuming mating types are constant over time) for intergametophytic selfing $(S)$ or intragametophytic selfing $\left(S_{\mathrm{I}}\right)$ should equal:

$$
H_{\mathrm{e}}=\frac{4 p q\left(1-S-S_{\mathrm{I}}\right)}{2-S}
$$

If outcrossing equals one (i.e. there is no selfing of any type) under the expectation of random mating the
Dioicous

observed heterozygosity should be equal to the expected heterozygosity. One-tailed $P$-values for the null hypothesis (selfing $=0$ ) versus the alternative (selfing $>0$ ) were calculated as the proportion of the iterations in which the observed heterozygosity of the original data were greater than or equal to the expected heterozygosity of the resampled genotypes.

In dioicous mosses, which have no intragametophytic selfing, if selfing rates were equal to one then $H_{\mathrm{e}}$ would equal zero. In monoicous mosses, if intragametophytic selfing was 1, intergametophytic selfing must be zero, and $H_{\mathrm{e}}$ would therefore also equal zero. For both breeding systems, to test whether $S$ or $S_{\text {I }}$ was significantly different from 1, we counted the proportion of the 10000 iterations in which the heterozygosity of the resampled genotypes was zero.

\section{Results}

\section{Population statistics}

For the five monoicous species, the mean species inbreeding coefficients were extremely high: $F_{\text {IS }}=0.89 \pm 0.12$ (s.e.), and ranged from 0.62 to 0.98 (Table 1). For the five dioicous species, mean inbreeding coefficients were much lower: $F_{\mathrm{IS}}=0.41 \pm 0.12$ (s.e.), ranging from 0.16 to 0.97 . For both the monoicous and dioicous species, $F_{\text {IS }}$ was significantly different from zero $\left(t_{1,18}=13.75 ; P=0.0002\right.$ and $t_{1,18}=2.83 ; P=0.05$, for monoicous and dioicous species, respectively), indicating that the average estimated frequency of heterozygotes diverged significantly from Hardy-Weinberg expectations. In each case, significant, positive values indicate a deficiency of heterozygotes, or significant substructure within populations. Additionally, $F_{\text {IS }}$ was significantly higher in monoicous species compared with dioicous species $\left(F_{1,24}=6.53, P=0.02\right)$. There were no significant effects of species or the covariate, number of allozyme loci $\left(\mathrm{F}_{8,24}=0.89, P=0.54\right.$ and $\mathrm{F}_{2,24}=0.28$, $P=0.76$, respectively).

On average, populations of the same species showed significant levels of genetic differentiation (Table 2). For both breeding systems, $F_{\mathrm{ST}}$ was significantly different from zero $\left(t_{1,4}=3.20, P=0.03\right.$ and $t_{1,4}=3.50, P=0.03$, for monoicous and dioicous species, respectively). For monoicous mosses, mean $F_{\mathrm{ST}}=0.56 \pm 0.07$ (s.e.) with a range from 0.37 to 0.78 , and for dioicous mosses, mean $F_{\mathrm{ST}}=0.55 \pm 0.02$ (s.e.) with a range from 0.09 to 0.61 . $F_{\mathrm{ST}}$ did not vary significantly between monoicous and dioicous moss species $\left(t_{1,8}=-0.25, P=0.81\right)$.

Table 2 Wright's measurement of population divergence $\left(F_{\mathrm{ST}}\right)$

\begin{tabular}{llc}
\hline Breeding system & Species & $\mathrm{F}_{S T}$ \\
\hline Monoicous & Acrocladium chlamydophyllum & 0.4860 \\
& Funaria hygrometrica & 0.6015 \\
& Rhynchostegium tenuifolium & 0.3672 \\
& Syntrichia antarctica & 0.7840 \\
& Tortula muralis & 0.5829 \\
& & \\
Dioicous & Hypnodendron arcuatum & 0.5584 \\
& Macromitrium longipes & 0.6089 \\
& Polytrichadelphus magellanicus & 0.5010 \\
& Hypopterygium filiculaeforme & 0.5498 \\
& & 0.0873 \\
\hline
\end{tabular}


Selfing rates

For the monoicous mosses, the amalgam of intergametophytic selfing and intragametophytic selfing is equivalent to the $F_{\mathrm{IS}}$ already given (mean \pm s.e. $=$ $0.88 \pm 0.12$; Table 1 ). In $35 \%$ of monoicous populations (six of 17), selfing rates were significantly different from zero, and in only $6 \%$ of monoicous populations (one of 17) were selfing rates significantly different from one. Among populations of dioicous mosses, the intergametophytic selfing rate ranged from -1.17 to 1.00 (mean \pm s.e. $=0.41 \pm 0.17$ ). In only $18 \%$ of dioicous populations (three of 17), intergametophytic selfing rates were significantly different from zero, while in $41 \%$ of dioicous populations (seven of the 17), selfing rates were significantly different from one (Table 1).

\section{Discussion}

Here, we show that moss species with combined sexes have levels of heterozygosity that diverge more from expectation than species with separate sexes. Only a handful of studies have used molecular markers to examine diploid moss tissue (Shaw, 2000); however, our result is consistent with two allozyme studies in mosses

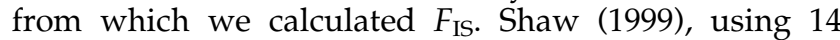
allozyme loci, found that in the monoicous moss Funaria hygrometrica, sporophytes were never heterozygous, suggesting an $F_{\text {IS }}$ value of one and high heterozygote deficiency. In contrast, Innes (1990) found exceedingly high levels of heterozygote excess in the dioicous moss Polytrichum juniperinum, using six allozyme loci $\left(F_{\mathrm{IS}}=-0.10 \pm 0.16\right.$; according to our calculations from the reported data). We infer from our results that the difference found by these researchers in the divergence of heterozygosity levels from expectations may be due to differences in breeding system.

Our results also suggest that levels of selfing may be high in monoicous mosses, and less so in many dioicous mosses. This finding is consistent with suggestions that monoicous mosses experience high levels of selfing (for reviews see Wyatt and Anderson, 1984; Wyatt, 1994). In dioicous populations, widespread spore dispersal may result in little spatial population structure and consequently low intergametophytic selfing (see Holsinger, 1987). If spore dispersal is widespread in mosses, negative $F_{\text {IS }}$ values in outcrossing species (such as those measured by Innes (1990) in Polytrichum and occur in several of the dioicous populations we sampled; Table 1) are not unexpected because gametophytic variability can be exceedingly low - one to two clones per population being the norm in many species (Shaw, 2000). As a result, one haploid genet may be the maternal parent and the other the paternal parent of all sporophytic individuals in an outcrossing population, and if the parental pair shares few alleles because of long-distance spore dispersal, a negative population-wide $F_{\text {Is }}$ will result. If widespread spore dispersal occurs in dioicous populations, then negative $F_{I S}$ values will be common, intergametophytic selfing will be low, and mean values of $F_{\text {IS }}$ for these dioicous species as a whole may be much lower than would be expected for monoicous species where even low levels of intragametophytic selfing occur.

Interestingly, in three populations of dioicous mosses from two species (Polytrichadelphus magellanicus; Polytrichaceae and Breutelia pendula; Bartramiaceae) selfing rates were significantly greater than zero. Thus, significant levels of intergametophytic selfing and/or biparental inbreeding do occur, and the breeding system of some populations of dioicous mosses may be more mixed mating than expected. This finding also suggests that it cannot be assumed that no intergametophytic selfing occurs in monoicous species: intergametophytic selfing depends on similar processes in both monoicous and dioicous mosses (spore dispersal and sperm movement), and it could be expected that levels may be similar in monoicous and dioicous mosses with similar life histories.

Differences in selfing rates are not the only explanation for significant differences in $F_{\text {IS }}$ between breeding systems (Hartl and Clark, 1997). For example, smallscale spatial structure within the sampled populations may lead to an overall deficiency of heterozygotes, for example, through a Wahlund effect (Wahlund, 1928). Under this scenario, mating system differences may result in changes to the frequency of matings between close neighbours. This could occur, for example, if splash cups found in males of some dioicous species result in increased sperm dispersal distances. While we did not test for spatial structuring of genotypes within populations, $F_{\text {IS }}$ did not differ between the dioicous species with splashcups ( $P$. magellanicus and $B$. pendula) and those without (Hypnodendron arcuatum, Macromitrium longipes, and Hypopterygium filiculaeforme), suggesting that the morphological differences that are often associated with a dioicous mating system do not always influence smallscale population structuring.

Another explanation for the differences in $F_{\text {IS }}$ between breeding systems may be a more frequent history of population bottlenecks in monoicous versus dioicous mosses. Indeed, the high variability in $F_{\text {IS }}$ measured within species suggests that demographic differences between populations may contribute to our estimates of

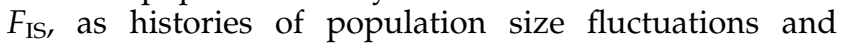
extinction/recolonization events have theoretically and empirically been found to contribute to heterozygote deficiency in other species (e.g. Viard et al., 1997; for a review see Hanski and Gaggiotti, 2004). Moreover, differences in selfing rates and population dynamics between breeding systems can be confounded as both high levels of selfing and a history of bottlenecks are likely to be characteristics of species with an ephemeral life-history (Baker, 1965; Hamrick and Godt, 1989; Schoen and Brown, 1991). The advantage to an individual in being able to self-fertilize during repeated colonization or recolonization events - and thus being able to establish a population on its own - is the most compelling current explanation for the evolution of selfcompatibility in a wide-range of unrelated plant taxa (see Pannell and Barrett, 1998 for a review).

Determining the relative importance of selfing and population bottlenecks for reducing heterozygosity excess is difficult; however, some of our data may be informative. Measurements of $F_{\mathrm{ST}}$ in monoicous and dioicous species did not differ significantly despite a significant difference in $F_{\text {IS. }}$. While the lack of differences found between the breeding systems could be an artefact of restricted sampling of allozyme loci (and indeed some of our estimates are higher than estimates between moss populations reported elsewhere; Shaw et al., 1990), it may also be due to the similar, disturbed habitat occupied by 
many of the monoicous and dioicous mosses we collected (e.g. monoicous F. hygrometrica, Tortula muralis, Syntrichia antarctica, and dioicous P. magellanicus and $B$. pendula). In more stable habitats, many mosses had few sporophytes, and thus we were unable to include these species in our collections. If monoicous species were more likely to undergo bottlenecks because of frequent colonization and/or recolonization events (see Freckleton and Watkinson, 2002; Hanski and Gaggiotti, 2004), and thus have higher levels of homozygosity, $F_{\mathrm{ST}}$ values would also be higher in monoicous species due to greater population differentiation (assuming that the number of individuals founding colonies is small relative to the number of migrants moving into extant populations; see Wade and McCauley, 1988). While values of $F_{\mathrm{ST}}$ will also increase in selfing populations (Wright, 1968; Hamrick and Godt, 1989), intragametophytic selfing will result in a complete loss of heterozygosity in one generation, and thus $F_{\text {IS }}$ should increase at a much faster rate. Our finding of no significant difference in $F_{\mathrm{ST}}$ between breeding systems may indicate that the significant difference we measured in heterozygote deficiency between monoicous and dioicous mosses is not due primarily to histories of bottlenecks, but either to a combination of bottlenecking and selfing, or to selfing alone.

Differences in selfing rates between breeding systems should influence levels of inbreeding depression in the sporophyte. In monoicous bryophytes, complete homozygosity after one generation of intragametophytic selfing suggests that levels of inbreeding depression will be extremely high at this stage (Hedrick, 1987a), but purging of deleterious alleles will result in no or little inbreeding depression in future generations, and selfing would likely be favoured. Under such conditions, the presence of separate sexes (dioicy) may seem unintuitive. One possibility is that the maintenance of separate sexes in haploid-dominant species may depend on the levels of intergametophytic selfing. If intergametophytic selfing in dioicous mosses is low or nonexistent (which in this study may be as many as $41 \%$ of the sampled dioicous populations), the accumulation of deleterious alleles at the diploid stage would lead to a high cost of selfing (e.g. through sporophyte abortion) and may maintain separate sexes. If intergametophytic selfing is universally high, then purging of deleterious alleles would occur (as in selfing in seed plants) and monoicy should be selected over dioicy in these species. In this situation, inbreeding depression is unlikely to be the explanation for the selection and maintenance of separate sexes in mosses, and other possibilities may include genetic constraints (particularly if dioicy is the ancestral condition), sexual specialization (Charlesworth, 1999) or fitness advantages to heterozygosity (Wright, 1968; Roff, 2002).

The evolution of biphasic lifecycles may also be influenced by selfing rates and the differential expression of inbreeding depression at the haploid and diploid stage. Theoretical work has suggested that selection for haploid-dominant life stages should be correlated with selfing, as deleterious alleles are revealed and more quickly eliminated by selection. In contrast, diploidy masks mutations and diploid dominance should be selected in outcrossing species (Otto and Marks, 1996). If having separate sexes is primarily an outcrossing mechanism, it is predicted that this breeding system would correlate with haploid dominance. Interestingly, separate sexes occur in 58\% of moss species (Wyatt and Anderson, 1984), compared to approximately $10 \%$ of angiosperm species (Geber et al., 1999), which is contrary to these predictions.

Breeding systems in haploid-dominant organisms are almost unknown, and yet may provide information on the evolution of diploidy from haploidy and may also provide a context to test theoretical models of breeding system evolution based on angiosperms (Lloyd, 1975; Charlesworth and Charlesworth, 1978). Measurements of selfing rates within and between gametophytes are needed, and algorithms exist to distinguish the two (Ritland et al., 1990). At present, estimates have been restricted by a lack of heterozygosity at allozyme loci, especially in monoicous populations. Microsatellite data may overcome these problems.

\section{Acknowledgements}

We thank M Crawford and L Milicich for help in the lab. We are grateful to J Beever, A Fife, P Garnock-Jones, B Malcolm, B Polly and A Shaw for help with collection and identification and E Baack, M Dorken and P Garnock-Jones for comments on earlier drafts of this manuscript. We thank the staff at the Museum of New Zealand Te Papa Tongarewa for access to and help with the bryophyte herbarium for collection comparisons. Research was supported by The Royal Society of New Zealand Marsden Fund (grant VUW 303 to LKJ).

\section{References}

Baker HG (1965). Characteristics and modes of origins of weeds. In: Baker HG, Stebbins GL (eds). The Genetics of Colonizing Species. Academic Press: New York, USA. pp 147-172.

Barrett SCH, Eckert CG (1990). Variation and evolution of mating systems in seed plants. In: Kawano S (ed). Biological Approaches and Evolutionary Trends in Plants. Academic Press: London. pp 229-254.

Carlon DB (1999). The evolution of mating systems in tropical reef corals. Trends Ecol Evol 14: 491-495.

Charlesworth B, Charlesworth D (1978). A model for the evolution of dioecy and gynodioecy. Am Nat 112: 975-997.

Charlesworth B, Charlesworth D (1998). Some evolutionary consequences of deleterious mutations. Genetica 103: 3-19.

Charlesworth D (1999). Theories of the evolution of dioecy. In: Geber MA, Dawson TE, Delph LF (eds). Gender and Sexual Dimorphism in Flowering Plants. Springer-Verlag: Berlin. pp 33-60.

Fisher RA (1949). The Theory of Inbreeding. Oliver and Boyd: London, UK.

Freckleton R, Watkinson A (2002). Large-scale spatial dynamics of plants: metapopulations, regional ensembles and patchy populations. J Ecol 90: 419-434.

Geber MA, Dawson TE, Delph LF (1999). Gender and Sexual Dimorphism in Flowering Plants. Springer-Verlag: Berlin.

Hamrick JL, Godt MJ (1989). Allozyme diversity in plant species. In: Brown AHD, Clegg MT, Kahler AL, Weir BS (eds). Plant Population Genetics, Breeding, and Genetic Resources. Sinauer: Sunderland, MA, USA. pp 43-63.

Hanski IA, Gaggiotti OE (2004). Ecology, Genetics and Evolution of Metapopulations. Elsevier: San Diego.

Hartl DL, Clark AG (1997). Principles of Population Genetics, 3rd edn. Sinauer Associates, Inc: Sunderland, Massachusetts.

Hedrick PW (1987a). Genetic load and the mating system in homosporous ferns. Evolution 41: 1282-1289. 
Hedrick PW (1987b). Population genetics of intragametophytic selfing. Evolution 41: 137-144.

Holsinger KE (1987). Gametophytic self-fertilization in homosporous plants: Development, evaluation, and application of a statistical method for evaluating its importance. Am J Bot 74: $1173-1183$.

Innes DJ (1990). Microgeographic genetic variation in the haploid and diploid stages of the moss Polytrichum juniperinum Hedw. Heredity 64: 331-340.

Jarne P, Charlesworth B (1993). The evolution of the selfing rate in functionally hermaphrodite plants and animals. Annu Rev Ecol Syst 24: 441-466.

Johnston MO, Das B, Hoeh WR (1998). Negative correlation between male allocation and rate of self-fertilization in a hermaphroditic animal. Proc Natl Acad Sci USA 95: 617-620.

Klekowski EJ (1979). The genetics and reproductive biology of ferns. In: Dyer AF (ed). The Experimental Biology of Ferns. Academic Press: London, UK. pp 133-170.

Lande R, Schemske DW (1985). The evolution of self-fertilization and inbreeding depression in plants. I. Genetic models. Evolution 39: 24-40.

Lloyd DG (1975). The maintenance of gynodioecy and androdioecy in angiosperms. Genetica 45: 325-339.

McCauley DE, Whittier DP, Reilly LM (1985). Inbreeding and the rate of self-fertilization in a grape-fern, Botrychium dissectum. Am J Bot 72: 1978-1981.

Nei M, Maruyama T, Chakraborty R (1975). The bottleneck effect and genetic variability in populations. Evolution 29: $1-10$.

Otto SP, Marks JC (1996). Mating systems and the evolutionary transition between haploidy and diploidy. Biol J Linn Soc 57: 197-218.

Pannell JR, Barrett SCH (1998). Baker's law revisited: reproductive assurance in a metapopulation. Evolution 52: 657-668.

Ritland K (1990). A series of FORTRAN computer programs for estimating plant mating systems. J Hered 81: 235-237.

Ritland K, Soltis DE, Soltis PS (1990). A two-locus model for the joint estimation of intergametophytic and intragametophytic selfing rates. Heredity 65: 289-296.

Roff DA (2002). Inbreeding depression: tests of the overdominance and partial dominance hypotheses. Evolution 56: 768-775.

SAS Institute (2004). JMP for Windows. SAS Institute: Cary, NC.
Schoen DJ, Brown AHD (1991). Intraspecific variation in population gene diversity and effective population size correlates with mating system in plants. Proc Natl Acad Sci USA 88: 4494-4497.

Shaw AJ (1991). The genetic structure of sporophytic and gametophytic populations of the moss, Funaria hygrometrica Hedw. Evolution 45: 1260-1274.

Shaw AJ (1999). Genetic structure in relation to reproductive biology of 11 species of Pohlia hedw (Bryaceae). Syst Bot 24: 85-94.

Shaw AJ (2000). Population ecology, population genetics and microevolution. In: Shaw AJ, Goffinet B (eds). Bryophyte Biology. Cambridge University Press: Cambridge. pp 369-402.

Shaw AJ, Werner O, Ros R (1990). Intercontinental Mediterranean disjunct mosses: morphological and molecular patterns. Am J Bot 90: 540-550.

Soltis DE, Soltis PA (1989). Isozymes in Plant Biology. Dioscorides Press: Portland, Oregon.

Soltis DE, Soltis PS (1992). The distribution of selfing rates in homosporous ferns. Am J Bot 79: 97-100.

Viard F, Justy F, Jarne P (1997). The influence of self-fertilization and population dynamics on the genetic structure of subdivided populations: a case study using microsatellite markers in the freshwater snail Bulinus truncatus. Evolution 51: 1518-1528.

Wade MJ, McCauley DE (1988). Extinction and recolonization: their effects on the genetic differentiation of local populations. Evolution 42: 995-1005.

Wahlund S (1928). Zusammensetzung von Populationen und Korrelationserscheinungen von Standpunkt der Vererbungslehre aus betrachtet. Hereditas 11: 65-106.

Wright S (1965). The interpretation of population structure by F-statistics with special regard to systems of mating. Evolution 19: 395-420.

Wright S (1968). Evolution and the Genetics of Populations. University of Chicago Press: Chicago, Ill, USA.

Wyatt R (1994). Population genetics of bryophytes in relation to their reproductive biology. J Hattori Bot Lab 76: 147-157.

Wyatt R, Anderson LE (1984). Breeding systems in bryophytes. In: Dyer AF, Duckett JG (eds). The Experimental Biology of Bryophytes. Academic Press: London. pp 39-64.

Yeh FC, Yang RC, Boyle T (1997). Popgene version 1.32. Software for Population Genetic Analysis. University of Alberta: Alberta. 